\title{
Synthetic tools for studying the chemical biology of InsP $\mathrm{P}_{\mathbf{8}}^{\dagger}$
}

Cite this: Chem. Commun., 2015, 51, 12605

Received 18th June 2015, Accepted 3rd July 2015

DOI: $10.1039 / \mathrm{c} 5 \mathrm{cc} 05017 \mathrm{k}$

www.rsc.org/chemcomm

To synthesise stabilised mimics of Ins $\mathrm{P}_{8}$, the most phosphorylated inositol phosphate signalling molecule in Nature, we replaced its two diphosphate (PP) groups with either phosphonoacetate (PA) or methylenebisphosphonate (PCP) groups. Utility of the PA and PCP analogues was verified by structural and biochemical analyses of their interactions with enzymes of Ins $\mathrm{P}_{8}$ metabolism.

The myo-inositol phosphates (InsPs) are a family of intracellular signalling molecules containing combinatorial arrangements of monophosphate (P) and diphosphate (PP) groups arranged around the hexahydroxycyclohexane ring of myo-inositol (Ins). ${ }^{1}$ There is much current interest in the specialised chemistry and biology of the diphosphoinositol polyphosphates (PP-InsPs, inositol pyrophosphates); ${ }^{2}$ recent research has highlighted the central roles that PP-InsPs play in cellular and organismic homeostasis in all eukaryotes. For example, PP-InsPs regulate DNA repair, ${ }^{3}$ immunity ${ }^{4,5}$ and metabolic homeostasis. ${ }^{6-8}$

The most studied of the PP-InsPs are 5-InsP $\mathrm{P}_{7}, 1-\mathrm{InsP}_{7}$ and $\mathrm{InsP}_{8}$ (Fig. 1), which are formed from InsP $_{6}$ by InsP $_{6}$ kinases (IP6Ks) and diphosphoinositol pentakisphosphate kinases (PPIP5Ks). ${ }^{9}$ The diphosphate groups that are produced by IP6K and PPIP5K are hydrolysed by a family of PP-InsP diphosphohydrolases (DIPPs), leaving monophosphate groups and liberating inorganic orthophosphate (Pi). ${ }^{10}$

Evidence has been obtained that the PP-InsPs non-enzymatically pyrophosphorylate a range of target proteins. ${ }^{11}$ It has also been reported that $5-\mathrm{InsP}_{7}$ produces a separate range of cellular

\footnotetext{
${ }^{a}$ Wolfson Laboratory of Medicinal Chemistry, Department of Pharmacy and Pharmacology, University of Bath, Claverton Down, Bath, BA2 7AY, UK

${ }^{b}$ Inositol Signaling Group, Laboratory of Signal Transduction,

National Institute of Environmental Health Sciences, National Institutes of Health, Research Triangle Park, North Carolina, USA

${ }^{c}$ Department of Pharmacology, University of Oxford, Mansfield Road, Oxford, OX1 3QT, UK. E-mail: barry.potter@pharm.ox.ac.uk; Fax: +44-1865-271853; Tel: $+44-1865-271945$

$\dagger$ Electronic supplementary information (ESI) available: Data deposition: atomic coordinates and structure factors have been deposited in the Protein Data Bank, www.pdb.org (PDB ID codes 5BYA and 5BYB). See DOI: 10.1039/c5cc05017k
}

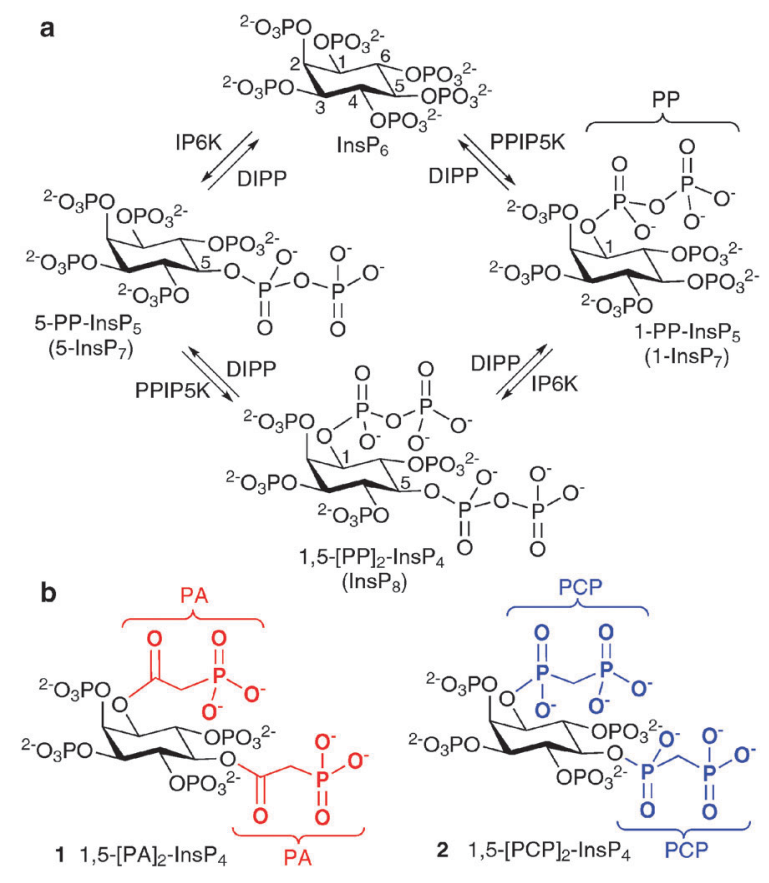

Fig. 1 (a) Biosynthesis of diphosphoinositol polyphosphates from myoinositol hexakisphosphate (InsP $\mathrm{P}_{6}$ ). IP6K, inositol hexakisphosphate 5-kinase; PPIP5K, diphosphoinositol pentakisphosphate kinase; DIPP, diphosphoinositol polyphosphate phosphohydrolase; (b) structures of synthetic $\alpha$-phosphonoacetic acid ester (PA) analogue 1 and methylenebisphosphonate (PCP) analogue 2

effects by interacting with pleckstrin homology ( $\mathrm{PH})$ domains of proteins. ${ }^{12}$ Additionally, in response to viral invasion, 1-InsP was recently shown to stimulate phosphorylation of IRF3, an activator of interferon transcription. ${ }^{5}$ No independent function for $\mathrm{InsP}_{8}$ has, however, yet been shown. Nevertheless, in mammalian cells, levels of $\mathrm{InsP}_{8}$ are regulated in a stimulus-dependent fashion, increasing several-fold following osmotic stress or thermal challenge, ${ }^{13}$ whereas bioenergetic stress decreases InsP $_{8}$ concentrations. ${ }^{7}$ Indeed, InsP $\mathrm{P}_{8}$ is the only PP-InsP so far shown to exhibit such acute, stimulus-dependent changes in 
its levels. Such responses are typically hallmarks of a signalling event, in which the concentration-dependent influence of a messenger upon a target protein (a receptor) is transduced into a biological response. It is therefore reasonable to consider the existence of $\mathrm{InsP}_{8}$ "receptors".

The structure of mammalian $\operatorname{InsP}_{8}$ has been identified ${ }^{14,15}$ as 1,5-[PP $]_{2}-\mathrm{InsP}_{4}$ (Fig. 1) and a chemical synthesis ${ }^{16}$ has provided isomerically pure material in the amounts required for detailed biological studies with cell extracts. However, in such experiments, the PP-InsPs are rapidly metabolised by phosphatases. Therefore, there is a need for synthetic InsP $_{8}$-based probes, especially stabilised analogues in which the labile diphosphate (PP) is replaced with mimics more resistant to chemical and enzymatic degradation. Such compounds could be used to screen for $\mathrm{InsP}_{8}$ receptors in cellular or tissue lysates and may have greater potential for further synthetic elaboration than InsP $_{8}$ itself. They may also be useful as mechanistic probes because they cannot substitute for the ability of InsP $_{8}$ to transfer a phosphate group to target proteins. ${ }^{11}$

Previously, we reported the syntheses of analogues of $5-\mathrm{InsP}_{7}$, in which the PP group is replaced with an $\alpha$-phosphonoacetic acid (PA) ester. ${ }^{17}$ Others have developed methylenebisphosphonate (PCP) analogues of 1 - and 5 - $\mathrm{InsP}_{7}{ }^{18}$ The synthesis of the corresponding $\mathrm{InsP}_{8}$ mimics is considerably more challenging, requiring introduction of two PP surrogates around an asymmetrically substituted myo-inositol hub of known absolute configuration. Here we report the syntheses of the PA and PCP analogues of $\operatorname{InsP}_{8}$, namely, 1,5-[PA $]_{2}-\mathrm{InsP}_{4}(1)$ and 1,5-[PCP $]_{2}$ - $\mathrm{InsP}_{4}(2)$, respectively.

The syntheses of 1 and 2 (Scheme 1) begins with diol (-)-3, obtained by regioselective reduction of 2,4,6-tri-O-benzyl myoinositol orthobenzoate, ${ }^{19}$ followed by optical resolution of racemic 3 via the formation of diastereoisomeric monocamphanate esters ${ }^{20}$ (see $\mathrm{ESI} \dagger$ for details) $\$$ For the synthesis of 1,5-[PA $]_{2}-\mathrm{InsP}_{4}(\mathbf{1})$, carbodiimide-mediated esterification of the two free hydroxyl groups in (-)-3 with diethylphosphonoacetic acid (4) proceeded smoothly to give diester 5. Hydrogenolytic cleavage of the benzyl protecting groups allowed isolation of tetraol $\mathbf{6}$, while avoiding the facile ester 1,2-migration. Phosphitylation of the exposed hydroxyl groups at C-2, C-3, C-4 and C-6 using bis(benzyloxy)diisopropylaminophosphine, followed by oxidation gave 7 . Treatment with TMSBr removed benzyl and ethyl ester protecting groups on phosphates and phosphonates respectively to give the per-silylated intermediate. Finally, cleavage of silyl esters with methanol followed by a simple work-up with aqueous triethylammonium bicarbonate gave 1,5-[PA $]_{2}-\mathrm{InsP}_{4}(\mathbf{1})$ as the triethylammonium salt. $\S$

The synthesis of 1,5-[PCP $]_{2}-\operatorname{InsP}_{4}$ (2) from (-)-3 was more challenging than the analogous synthesis of $\mathbf{1}$, essentially due to two complicating factors. First, introduction of two tri-protected PCP moieties at O-1 and O-5 of (-)-3 results in the formation of stereogenic centres at P-1 and P-5. The required product will therefore consist of a mixture of four diastereoisomers.

Second, phosphonylation of the sterically hindered secondary hydroxyl groups in (-)-3 proved to be much more difficult than their acylation. Initial attempts at carbodiimide-mediated condensation of (-)-3 with the triethyl ester of methylenebisphosphonic acid (8) gave no product. Reaction of $(-)-3$ with the phosphonochloridate derived from 8 in pyridine gave only the 1-bisphosphonate as a mixture of two diastereoisomers. Trials using this phosphonochloridate with other bases and solvents gave the desired product $\mathbf{9}$, but only in unacceptably low yields. More promising results were obtained using DIPEA in dichloromethane; $\uparrow$ under these conditions, 9 was obtained in 15\% yield after flash chromatography, together with larger amounts of monophosphonylated material (in this case, a mixture of 1- and 5-bisphosphonates), which could be recycled to give more 9. In this way, 9 was obtained as an inseparable mixture of four diastereoisomers (ratio approx. $3: 3: 1: 1$ by NMR) in a total yield of $30 \%$ after one round of recycling. Further recycling to give more 9 was possible, but was not carried out.

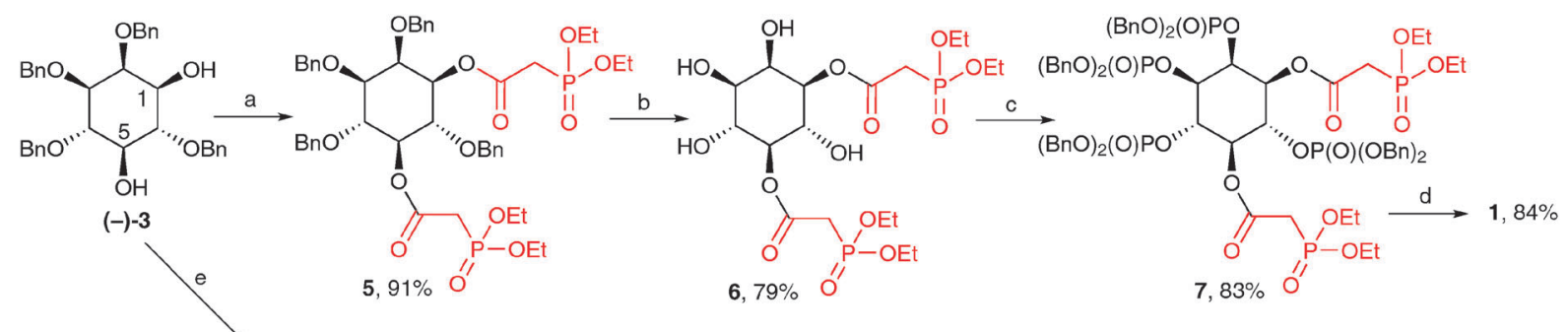

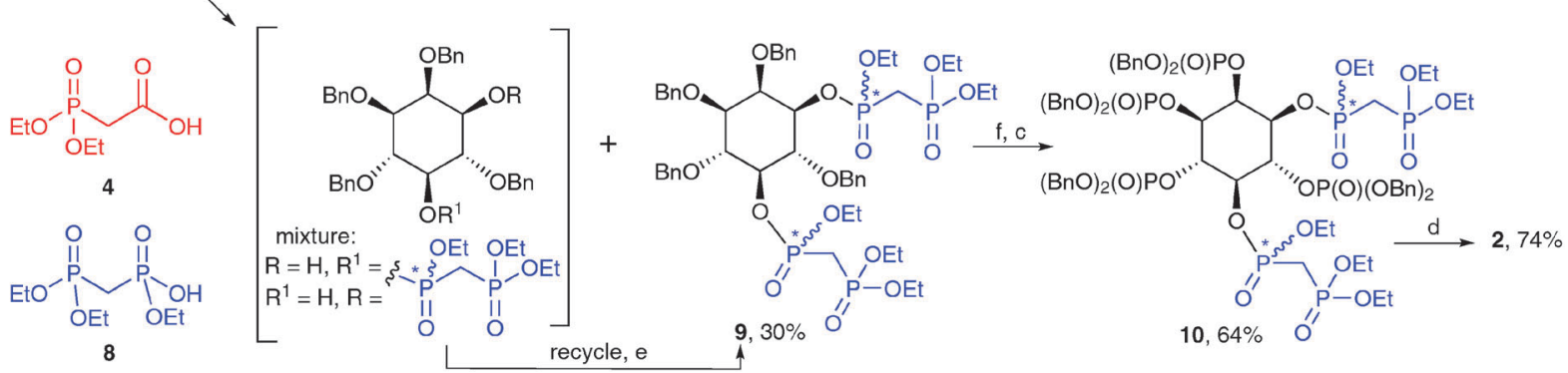

Scheme 1 Synthesis of 1 and 2. Reagents and conditions: (a) EDAC, 4, $\mathrm{CH}_{2} \mathrm{Cl}_{2}$; (b) $\mathrm{H}_{2}, \mathrm{Pd}(\mathrm{OH})_{2} / \mathrm{C}, \mathrm{MeOH}_{2} \mathrm{H}_{2} \mathrm{O}$; (c) i. (BnO) ${ }_{2} \mathrm{PNPr}$, 5-phenyl-1Htetrazole, $\mathrm{CH}_{2} \mathrm{Cl}_{2}$; ii. $\mathrm{mCPBA}, \mathrm{CH}_{2} \mathrm{Cl}_{2}$; (d) i. TMSBr, $\mathrm{CH}_{2} \mathrm{Cl}_{2}$; ii. $\mathrm{MeOH}$, TEAB; (e) (EtO) ${ }_{2} \mathrm{P}(\mathrm{O}) \mathrm{CH}_{2} \mathrm{P}(\mathrm{O})(\mathrm{OEt}) \mathrm{Cl}$, DIPEA, $\mathrm{CH}_{2} \mathrm{Cl}_{2}$; (f) $\mathrm{H}_{2}, \mathrm{Pd}(\mathrm{OH})_{2} / \mathrm{C}, \mathrm{MeOH}$, $\mathrm{THF}$, $\mathrm{H}_{2} \mathrm{O}, \mathrm{AcOH}$. TEAB, aqueous triethylammonium bicarbonate; Bn, benzyl. Yields are shown in respect of each step. Stereogenic phosphorus atoms are indicated by an asterisk. 
Removal of the benzyl protecting groups from 9 followed by phosphitylation and oxidation gave fully protected 10, again as a mixture of four diastereoisomers. The NMR spectra of $\mathbf{1 0}$ were highly complex, with at least 30 lines in the ${ }^{31} \mathrm{P}$ NMR spectrum (see ESI $\dagger$ ). However, on global deprotection with TMSBr followed by cleavage of silyl esters with methanol, the stereogenic centres at phosphorus were abolished, at last revealing the expected pattern of NMR signals for 1,5-[PCP $]_{2}-\mathrm{InsP}_{4}(2)$, which was isolated as the triethylammonium salt after ion-exchange chromatography.

When we incubated either InsP $\mathrm{P}_{8}$ analogue 1 or 2 with DIPP, we did not detect any Pi release. Next, we examined the interactions of $\mathbf{1}$ and $\mathbf{2}$ with the highly specific kinase domain of human PPIP5K2 (PPIP5K2 ${ }^{\mathrm{KD}}$ ). We have previously found that the reaction catalysed by PPIP5K $2^{\mathrm{KD}}$ is reversible in vitro, yielding ATP when PPIP5K2 $2^{\mathrm{KD}}$ is incubated with $\mathrm{ADP}$ and $\operatorname{InsP}_{8}{ }^{21}$ Detection of the generated ATP with luciferin/luciferase provides a sensitive assay for the reverse kinase reaction..$^{17,21,22}$ No ATP was detected using 1 or 2 in these assays (data not shown).

Previously, ${ }^{15}$ we obtained enzyme-product complexes by soaking InsP $_{8}$ into crystals of PPIP5K2 ${ }^{\mathrm{KD}}$ containing ADP. In the present work, we soaked product analogues $\mathbf{1}$ and $\mathbf{2}$ into similarly prepared crystals of PPIP $5 \mathrm{~K} 2{ }^{\mathrm{KD}}$. X-ray analyses showed that both compounds bound to the catalytic site of PPIP5K2 $2^{\mathrm{KD}}$ (Fig. 2). Significantly, the PA-containing analogue 1 was also observed in a second binding site, the function of which was previously demonstrated to enhance capture of substrate from the bulk phase. ${ }^{22}$ In this respect, compound 2 more closely mimics natural InsP $\mathrm{P}_{8}$, which was also found to occupy exclusively the catalytic site. ${ }^{15,16}$ This should not be taken to mean that $\mathrm{InsP}_{8}$ and 2 do not also bind to the capture site but that, presumably, they occupy it only transiently. Thus, the PA compound 1 provides additional insights into a subsequent step of the catalytic cycle; the transfer of newly-formed $\mathrm{InsP}_{8}$ to the capture site prior to release. Notably, the 1-PA group of $\mathbf{1}$ is solvent-exposed and has no interactions with the capture/ release site. This is consistent with the requirement that the site must bind both substrate (without 1-PP) and product (with 1-PP); it also suggests a suitable attachment point for reporter groups in probes designed to target this site.

In conclusion, we report the syntheses of two stabilised analogues of $\operatorname{InsP}_{8} ; 1,5-[\mathrm{PA}]_{2}-\mathrm{InsP}_{4}(1)$ and 1,5-[PCP $]_{2}-\mathrm{InsP}_{4}(2)$. Our observation that the PA analogue 1 occupies the capture/ release site in PPIP5K2 reveals how $\mathrm{InsP}_{8}$ mimics can give insight into different enzyme states within the overall catalytic cycle. Stabilised mimics will also be useful for identifying receptors within cell lysates. Since these two new probes might interact with receptors in subtly different ways, the use of both may increase opportunities to capture $\mathrm{InsP}_{8}$ receptors. The differing and complementary interactions of $\mathbf{1}$ and 2 with PPIPK2 (Fig. 2) illustrate this point.

Cellular levels of $\operatorname{InsP}_{8}$ are subject to stimulus-dependent regulation, yet it remains an orphan signal; no specific $\operatorname{InsP}_{8}$ receptor has yet been identified. Nevertheless, $\operatorname{InsP}_{8}$, which possesses the most crowded array of phosphate groups in Nature, demands from the cell a significant investment in energy to sustain its levels against a backdrop of high ongoing turnover. With recent advances in delivering PP-InsPs (and hence PP-InsP mimics) into cells, ${ }^{23}$ it should now become possible to screen for biological effects of $\operatorname{InsP}_{8}$, and $\operatorname{InsP}_{8}$ mimics, in intact cells.

B.V.L.P. is a Wellcome Trust Senior Investigator (Grant 101010). This research was also supported by the Intramural
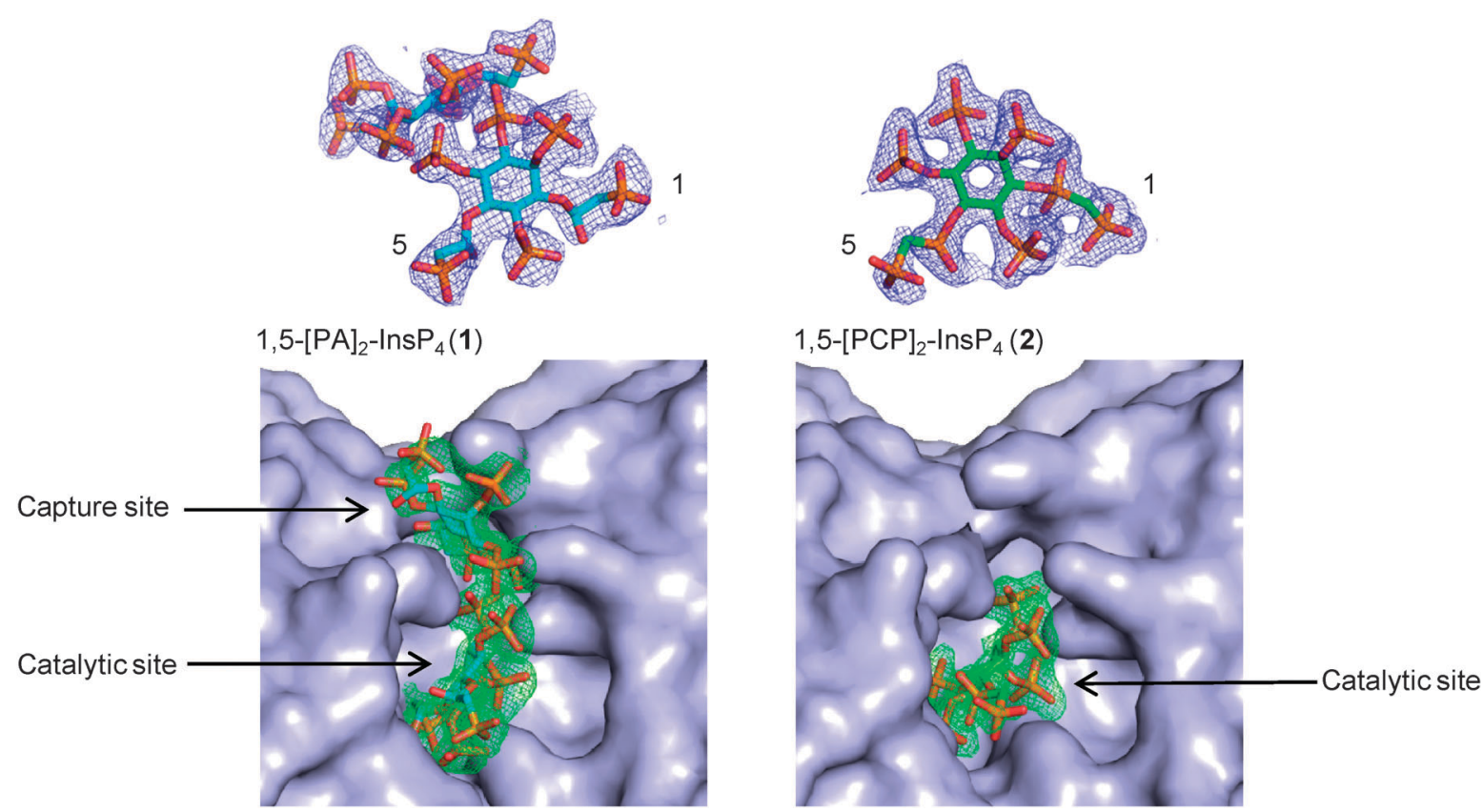

Fig. 2 Refined $2 F_{\mathrm{o}}-F_{\mathrm{c}}$ maps contoured at $1.0 \sigma$ for both compounds (top) and simulated annealing omit maps $\left(F_{\mathrm{o}}-F_{\mathrm{c}}\right.$, bottom panels) contoured at $2.0 \sigma$ for 1,5-[PA $]_{2}-\operatorname{InsP}_{4}(\mathbf{1})$ and 3.0 for 1,5-[PCP $]_{2}-\operatorname{InsP}_{4}$ (2). Compounds are shown as stick models. Carbon atoms are shown in cyan (1) or green (2), oxygen atoms in red, nitrogen atoms in blue, and phosphorus atoms in orange. The protein is shown as a surface representation. 
Research Program of the NIH/National Institute of Environmental Health Sciences.

\section{Notes and references}

\$ The required starting material (-)-3 was found to have the opposite specific rotation to that previously reported for $1 \mathrm{D}-2,3,4,6$-tetra-Obenzyl-inositol. ${ }^{20}$ The correct absolute configuration for (-)-3 was determined in the present work (see ESI $\dagger$ for details).

$\S$ Although the acyl esters in $\mathbf{1}$ will be susceptible to hydrolytic cleavage at high $\mathrm{pH}$, the ${ }^{31} \mathrm{P}$ NMR spectrum of a solution of the triethylammonium salt of 1 in $\mathrm{D}_{2} \mathrm{O}$ was unchanged after $>1$ year at $4{ }^{\circ} \mathrm{C}$.

T We found that the nature and pattern of protecting groups strongly influenced the outcome of the reaction. Phosphonylation of less sterically hindered substrates at either O-1 or O-5 was high-yielding under these conditions.

1 A. J. Hatch and J. D. York, Cell, 2010, 143, 1030.

2 A. Chakraborty, S. Kim and S. H. Snyder, Sci. Signaling, 2011, 4, re1; M. S. C. Wilson, T. M. Livermore and A. Saiardi, Biochem. J., 2013, 452, 369-379; S. B. Shears, Adv. Biol. Regul., 2015, 57, 203-216.

3 F. Rao, J. Cha, J. Xu, R. Xu, M. S. Vandiver, R. Tyagi, R. Tokhunts, M. A. Koldobskiy, C. Fu, R. Barrow, M. Wu, D. Fiedler, J. C. Barrow and S. H. Snyder, Mol. Cell, 2014, 54, 119-132.

4 A. Prasad, Y. Jia, A. Chakraborty, Y. Li, S. K. Jain, J. Zhong, S. G. Roy, F. Loison, S. Mondal, J. Sakai, C. Blanchard, S. H. Snyder and H. R. Luo, Nat. Immunol., 2011, 12, 752-760.

5 N. K. Pulloor, S. Nair, K. McCaffrey, A. D. Kostic, P. Bist, J. D. Weaver, A. M. Riley, R. Tyagi, P. D. Uchil, J. D. York, S. H. Snyder, A. Garcia-Sastre, B. V. L. Potter, R. Lin, S. B. Shears, R. J. Xavier and M. N. Krishnan, PLoS Pathog., 2014, 10, e1003981.

6 C. J. Barker, I. B. Leibiger, B. Leibiger and P. O. Berggren, Am. J. Physiol.: Endocrinol. Metab., 2002, 283, E1113-E1122.

7 K. Choi, E. Mollapour, J. H. Choi and S. B. Shears, Mol. Pharmacol., 2008, 74, 527-536.

8 Z. Szijgyarto, A. Garedew, C. Azevedo and A. Saiardi, Science, 2011, 334, 802-805.

9 M. P. Thomas and B. V. L. Potter, FEBS J., 2014, 281, 14-33.
10 S. T. Safrany, J. J. Caffrey, X. Yang, M. E. Bembenek, M. B. Moyer, W. A. Burkhart and S. B. Shears, EMBO J., 1998, 17, 6599-6607; R. S. Kilari, J. D. Weaver, S. B. Shears and S. T. Safrany, FEBS Lett., 2013, 587, 3464-3470.

11 R. Bhandari, A. Saiardi, Y. Ahmadibeni, A. M. Snowman, A. C. Resnick, T. Z. Kristiansen, H. Molina, A. Pandey, J. K. Werner Jr., K. R. Juluri, Y. Xu, G. D. Prestwich, K. Parang and S. H. Snyder, Proc. Natl. Acad. Sci. U. S. A., 2007, 104, 15305-15310.

12 H. B. R. Luo, Y. E. Huang, J. M. C. Chen, A. Saiardi, M. Iijima, K. Q. Ye, Y. F. Huang, E. Nagata, P. Devreotes and S. H. Snyder, Cell, 2003, 114, 559-572; N. A. Gokhale, A. Zaremba, A. K. Janoshazi, J. D. Weaver and S. B. Shears, Biochem. J., 2013, 453, 413-426.

13 X. Pesesse, K. Choi, T. Zhang and S. B. Shears, J. Biol. Chem., 2004, 279, 43378-43381; K. Choi, E. Mollapour and S. B. Shears, Cell. Signalling, 2005, 17, 1533-1541.

14 H. Lin, P. C. Fridy, A. A. Ribeiro, J. H. Choi, D. K. Barma, G. Vogel, J. R. Falck, S. B. Shears, J. D. York and G. W. Mayr, J. Biol. Chem., 2009, 284, 1863-1872.

15 H. Wang, J. R. Falck, T. M. Hall and S. B. Shears, Nat. Chem. Biol., 2012, 8, 111-116.

16 S. Capolicchio, H. Wang, D. T. Thakor, S. B. Shears and H. J. Jessen, Angew. Chem., Int. Ed., 2014, 53, 9508-9511.

17 A. M. Riley, H. Wang, J. D. Weaver, S. B. Shears and B. V. L. Potter, Chem. Commun., 2012, 48, 11292-11294.

18 M. Wu, B. E. Dul, A. J. Trevisan and D. Fiedler, Chem. Sci., 2013, 4, 405-410; M. Wu, L. S. Chong, S. Capolicchio, H. J. Jessen, A. C. Resnick and D. Fiedler, Angew. Chem., Int. Ed., 2014, 53, 7192-7197.

19 J. M. Swarbrick, S. Cooper, G. Bultynck and P. R. J. Gaffney, Org. Biomol. Chem., 2009, 7, 1709-1715.

20 P. Westerduin, H. A. M. Willems and C. A. A. van Boeckel, Tetrahedron Lett., 1990, 31, 6915-6918.

21 J. D. Weaver, H. Wang and S. B. Shears, Biosci. Rep., 2013, 33, 229-242.

22 H. Wang, H. Y. Godage, A. M. Riley, J. D. Weaver, S. B. Shears and B. V. L. Potter, Chem. Biol., 2014, 21, 689-699.

23 I. Pavlovic, D. T. Thakor, L. Bigler, M. S. C. Wilson, D. Laha, G. Schaaf, A. Saiardi and H. J. Jessen, Angew. Chem., Int. Ed., 2015, DOI: $10.1002 /$ anie.201503094. 